\title{
A COMPARATIVE NONPARAMETRIC ANALYSIS ON CRYPTO CURRENCY EXCHANGE RATE RETURNS
}

\author{
DOI: 10.17261/Pressacademia.2020.1344 \\ PAP- V.12-2020(8)-p.35-39
}

\section{Neslihan Fidan Kececi}

Istanbul University, School of Business, Quantitative Methods Department, Istanbul, Turkey. neslihan@istanbul.edu.tr, ORCID: 0000-0003-3007-9963

\section{To cite this document}

Fidan Kececi, N. (2020). A comparative nonparametric analysis on crypto currency exchange rate returns. PressAcademia Procedia (PAP), V.12, p.35-39.

Permanent link to this document: http://doi.org/10.17261/Pressacademia.2020.1344

Copyright: Published by PressAcademia and limited licensed re-use rights only.

\begin{abstract}
Purpose- Cryptocurrencies market have grown considerably since 2008 in terms of number and frequency of transactions, despite their advantages and disadvantages. Therefore cryptocurrency market is addressed frequently by financial and government institutions globally. Cryptocurrencies, which provide advantages in terms of time and costs such as instant transactions and low transfer fees, are seen as an alternative financial asset for investors. Therefore, cryptocurrency holders purposing of investing in its exchange rates are exposed to market risk. The purpose of this study is to compare the effectiveness of cryptocurrency exchange rate returns with respect to each other.

Methodology- The relative efficiencies of exchange rate returns are compared with the second order stochastic dominance criterion. As a nonparametric approach Stochastic dominance is used in analyzing the risk of financial return series that do not exhibit a normal distribution. Findings- When the exchange rate returns of five different cryptocurrencies are compared with the second order stochastic dominance criterion, it is determined that there are effective currencies among the cryptocurrency returns in the said period. On the other hand, it is seen that there are currencies that do not have stochastic dominance among the cryptocurrency returns.

Conclusion- The results results provide ideas for investors and researchers who want to include cryptocurrencies in their portfolios.
\end{abstract}

Keywords: Cryptocurrency, exchange rate risk, stochastic dominance, VaR, value at risk

JEL Codes: E44, G01, G32

\section{KRIPTOPARA DÖVIZ KURU GETIRILERI ÜZERINE KARȘILAȘTIRMALI NONPARAMETRIK BiR ANALIZ}

\section{ÖZET}

Amaç- Kriptopara birimleri 2008'den bu yana, avantaj ve dezavantajlarına rağmen sayı ve işlem sıklı̆ı̆ açısından oldukça büyüme göstermektedirler. Büyüyen kriptopara piyasası küresel olarak finans ve devlet kurumları tarafından da sıklıkla ele alınmaktadır. Anlık işlem yapabilme ve düşük transfer ücretleri gibi zaman ve maliyetler açııından avantajlar sağlayan kriptoparalar yatırımcılar açısından da alternatif bir finansal varlık olarak görülmektedirler. Dolayısıyla kriptopara kurlarındaki yatırım amacıyla kriptopara tutanları piyasa riskine maruz bırakmaktadır. Bu çalışmanın amacı kriptopara döviz kuru getirilerinin birbirlerine göre etkinliklerinin karşılaştırılmasıdır.

Yöntem- Döviz kuru getirilerinin birbirlerine göre etkinlikleri ikinci dereceden stokastik baskınlık kriteri ile karşılaştırılmışır. Stokastik baskınlık özellikle normal dağılım sergilemeyen finansal getiri serilerinin riskinin analizinde başvurulan herhangi bir dağılım varsayımına dayanmayan nonparametrik bir yaklaşımdır.

Bulgular- İslem hacmi en yüksek 5 farklı kriptopara biriminin döviz kuru getirileri karşılaştırıldığında söz konusu dönemde kriptopara getirileri arasında ikinci dereceden stokastik baskın olarak elde edilen para birimleri tespit edilirken, diğer kriptopara getirilerine karşı etkin olmayan para birimleri olduğu da görülmektedir.

Sonuç- Karşılaştırma sonuçları, kriptoparaları portföylerine dahil etmek isteyen yatıımcılara ve araştırmacılara ışık tutmaktadır.

Keywords: Kriptopara, döviz kuru riski, stokastik baskınlık, VaR, riske maruz değer

JEL Codes: E44, G01, G32

\section{Giriş}

Son yıllarda oldukça büyüyen kriptopara piyasası küresel olarak finans ve devlet kurumları tarafından da sıklıkla ele alınmaktadır. Binlerce çeşit kriptopara birimi içerisinden kapitalizasyonunun büyüklüğü nedeniyle en fazla bilineni Bitcoin'dir. 2020 yılı itibariyle en yüksek piyasa değerine sahip kripto para Bitcoin (BTC)'i sırasıyla Ether (ETH), Ripple (XRP), Tether (USDT) ve Bitcoin Cash (BCH) takip etmektedir 
(CoinMarket, 2020). Kriptopara birimleri 2008'den bu yana, avantaj ve dezavantajlarına rağmen sayı ve işlem sıklığı açısından oldukça büyüme göstermektedirler. Anlık işlem yapabilme ve düşük transfer ücretleri gibi zaman ve maliyetler açısından avantajlar sağlayan kriptoparalar ölçeklendirme, siber güvenlik ve volatilite gibi dezavantajları da taşımaktadırlar. Yatırımcılar açısından ise normallik varsayımını ihlal eden kriptopara fiyatlarındaki değişimler, alternatif bir finansal varlık olarak görülmelerini sağlamıştır. Kriptopara birimlerinin, fiyat hareketliliklerindeki oynaklık nedeniyle geleneksel para birimlerine göre daha değişken ve dolayısıyla daha riskli oldukları bilinmektedir (Osterrieder ve Lorenz, 2017; Phillip, Chan ve Peiris, 2018; Gkillas ve Katsiampa, 2018).

Risk yönetimi ve portföy analizi açısından kriptoparaların piyasada hangi yeteneklere sahip olduğunun ortaya çıkarılması yatırımcılar için önem taşımaktadır. Genel olarak Bitcoin, ortak pek çok özellikleri olduğundan iktisatçılar tarafından, altın ile karşılaştırılmaktadır. Hem Bitcoin hem de altın, değerlerinin çoğunlukla çıkarmanın az ve maliyetli olmasından almaktadır (Dyhrberg, 2016). İkisinin de uyruğu yok, her iki varlık da bir hükümet tarafından kontrol edilmiyor ancak birkaç bağımsız operatör ve şirket tarafından sürüldüğünden arz, yönetim ve kontrol süreçleri farklılık taşımaktadır. Glaser vd. (2014), Bitcoin borsasının ticaret verileri, Bitcoin Blockchain'den işlem verileri, Bitcoin Wikipedia makalesi için ziyaretçi istatistikleri ve önemli Bitcoin olaylarının tarihleri gibi bilgiler ışığında, Bitcoin'i ilk kez satın alan borsa kullanıcılarının, mal veya hizmetlerin ödemesi için kullanmak yerine bu Bitcoinleri spekülasyon amacıyla takas cüzdanlarında tuttuklarını belirtmişlerdir. Çalışmalarındaki bu sonucu ayrıca, Bitcoin fiyatlarının kriptopara birimiyle ilgili haberlerden etkilenmesi, kullanıcı taleplerinin borsada işlem gören Bitcoin hacmi üzerinde etkili olması ancak Bitcoin sistemi içindeki hacim üzerinde etkisi olmaması durumuyla desteklemektedirler. Kuzu ve Çelik (2020) Bitcoin ile diğer geleneksel yatırım araçları arasında uzun vadede eş bütünleşme ilişkisi görülmemesine ve mikro açıdan taşıdığı risklere rağmen Bitcoin'in portföy çeşitlendirme aracı olarak düşünülebileceğine değinmektedirler. Kriptopara üzerine yapılan analizler, piyasada ne tür bir role sahip olduklarını ortaya çıkarmak açısından önemlidir.

Bu makale, bir yatırım aracı olarak kullanılması durumunda, kriptopara birimlerinin fiyat değişimleri ile oluşan getirilerinde maruz kalınacak riskin ölçülmesine odaklanmaktadır. Finans alanında geleneksel olarak bilinen R-kare, Sharpe oranı ve beta gibi risk ölçüleri kullanılmaktadır. Bir diğer risk ölçüsü ise temeli 1960'lara dayanan Stokastik Baskınlık kriteridir. Kriptopara döviz kuru getirileri, yüksek volatilite ve birbirleri arasında korelasyon sergilemektedirler. Ayrıca normal dağılım özelliğini de sağlamamaktadırlar. Stokastik baskınlık özellikle normal dağılım sergilemeyen finansal getiri serilerinin riskinin analizinde başvurulan herhangi bir dağılım varsayımına dayanmayan nonparametrik bir yaklaşımdır. Bu çalışmada, kriptopara döviz kuru getirilerinin birbirlerine göre etkinlikleri ikinci dereceden stokastik baskınlık kriteri ile karşılaştırılmıştır.

\section{LITERATÜR}

Etkin olmayan finansal piyasalarda, yatırımcıların getiriler üzerine analiz ve tahminler yaparak pozisyon almasları mümkün olabilmektedir. Ancak kriptopara kurlarındaki dalgalanmalar işlem yapmak veya borsada kullanmak amacıyla kriptopara tutanları piyasa riskine maruz bırakmaktadır (Atıcı, 2020). Yapılan çalışmalarda kriptopara fiyatlarında artan trend ve getirilerinde oluşan yüksek volatilite risk unsuru olarak gösterilmektedir (Stavroyiannis, 2018; Güleç, Çevik ve Bahadır, 2018; Şahin ve Özkan, 2018). Başta Bitcoin olmak üzere farklı kriptoparaların volatilitelerinin modellenmesine ilişkin anlamlı sonuçlar içeren pek çok çalışma bulunmaktadır (Glaser vd., 2014; Dyhrberg, 2016; Katsiampa, 2017; Güleç, 2019; Katsiampa, Corbet ve Lucey, 2019; Ertuğrul, 2019; Silahli vd., 2019; Bouri, Lucey ve Roubaud, 2020; Jiménez, MoraValencia ve Perote, 2020; Kayral, 2020; Platanakis ve Urquhart, 2020). Asimetrik volatilite modellerini uyguladığı çalışmasında Akkuş ve Çelik (2020) Bitcoin getiri volatilitesinde uzun hafızanın varlığı tespit etmiş ve Bitcoin piyasasındaki pozitif haber şoklarının negatif haber şoklarına kıyasla volatiliteyi daha fazla arttırdığı sonucuna varmıştır. Dolayısıyla Bitcoin fiyatlarındaki oynaklık kamuya açıklanan bilgilerden de etkilenmektedir (Bartos, 2015). Teorik olarak asimetrik bilgi ortamının hakim olduğu ve fiyat hareketlerinin spekülatif nedenlerden etkilendiği bir kriptopara piyasasında, teknik analiz yöntemleri kullanılarak fiyatlar önceden tahmin edilebilir (Uyar, Kelten ve Moralı, 2020).

Karaağaç ve Altınırmak (2018) en yüksek piyasa değerine ve bunun yanında yüksek işlem hacmine sahip 10 kriptopara birimlerinin, Konuşkan vd. (2019) ise Bitcoin ile Ether ve Ripple kriptopara birimlerinin fiyat hareketlerini nedensellik ilişkisiyle inceleyerek kısa dönemde etkileşim içinde olduklarını ortaya koymuşlardır. Kanat ve Öget (2018) analizleri sonucunda, İngiltere (FTSE), Amerika Birleşik Devletleri (S\&P 500) ve Kanada (STSX) Borsasının, Bitcoin fiyatının dalgalanması hakkında kısa vadede fikir verebileceği dolayısıyla yatırımcıların Bitcoin'e yatırım yaparak risklerini çeşitlendirme yoluna gidebileceği kanaatindedirler. Bunun yanında Kılıç ve Çütçü (2018) BIST-100 endeksi ile Bitcoin fiyatları arasında orta ve uzun vadede bir eşbütünleşme etkisinin bulunmadığını tespit etmişlerdir. Benzer şekilde Azimov ve Alkan (2019) ekonometrik analizleri sonucunda Çin ve Rusya'nın ulusal para birimlerin dolar karşısındaki kuru, bu ülkelerin ulusal rezervleri ve piyasa endeksleri ile Bitcoin'in dolar karşısındaki performansını araştırmış ve fiyat serilerinin uzun vadede eşbütünleşik ilişkili oldukları sonucuna varmışlardır. Tüm bu çalışmaların sonuçları unutulmamalıdır ki kapsadığı dönemi bağlamaktadır. Gül (2020), çalışmasında kriptoparaların portföy çeşitlendirmesindeki performanslarını değerlendirmiştir. Hisse senetleri, emtialar, döviz kurları ve yatırım fonlarından meydana gelen portföylere ayrıca kriptoparaların eklenmesiyle, genel olarak daha yüksek getiri ve daha düşük risk seviyelerine ulaşıldığını görmüştür. Dolayısıyla, kriptoparaların portföy çeşitlendirmesinde kullanılabileceği sonucuna varmıştır. Yağmur ve Mangır (2020), yine Bitcoin fiyatlarındaki hareketlilik nedeniyle, parasal niteliğindense kısa vadeli spekülatif bir finansal yatırım aracı olma özelliğine dikkati çekmişlerdir. Koutmos (2019), farklı bir yatırım aracı olarak ortaya çıkan Bitcoin'in, ekonomik değişkenlere göre görünüşte ilgi çekici bağımsız davranıştaki fiyatlarına rağmen, geleneksel finansal varlıklarıyla aynı tür piyasa risklerine maruz kalabileceği konusunda uyarmaktadır.

Geleneksel portföylere, kriptoparaların dahil edilmesiyle sağlanan faydalar üzerine çalışmalar; kriptoparaların portföy riskinin düşürülmesinde etkili olduklarını ve aynı zamanda portföy çeşitlendirmede de alternatif olduklarına değinmektedirler: Dyhrberg, 2016; Ibragimov ve Prokhorow, 2016; Andrianto ve Diputra, 2017; Chuen, Guo ve Wang, 2017; Mba, Pindza ve Koumba,2018; Borri, 2019; Brauneis ve Mestel,2019; Liu,2019; Bouri, Lucey ve Rouboud, 2020; Platanakis ve Urquhart, 2020.

Finansal yatırımlarda ilgili tüm taraflar, kriptopara birimlerinin fiyat hareketlerindeki oynaklıktan kar kaybına uğrayarak etkilenebilmektedir (Likitratcharoen vd., 2018). Bu nedenlerle kriptopara birimlerinin fiyatlarındaki oynaklık borsada kullanıcıların ilgisinde olmaktadır. Kriptopara 
getirilerinin ikinci dereceden stokastik baskınlık kriteri ile etkinlik analizi üzerine çalışmalar oldukça azdır. İkinci dereceden stokastik baskınlığı kriptopara içeren portföy yatırımlarında kullanan çalışmalar; Anyfantaki, Arvanitis ve Topaloglou, 2018; Topaloglou ve Tsomidis, 2018 ve Belhadj ve Ben Hamad, 2019.

\section{VERI VE YÖNTEM}

Analizde ikinci dereceden stokastik baskınlık kriteri ile kriptopara getirilerinin birbirlerine göre etkinlikleri ikişerli karşılaştırmalarla incelenmiştir. 01.03.2019 ile 31.10.2020 tarihleri arasında, En yüksek piyasa değerine sahip ilk 10 kriptopara biriminin ABD doları cinsinden değerler, Bitcoin (btc), Etherium (eth), Tether (usdt), XRP (xrp), Bitcoin Cash (bch), Chainlink (link), Binance Coin (bnb), Litecoin (Itc), (Polkadot), USD Coin (usdc), Cordano (ada). https://coinmarketcap.com/ (02.11.2020)

Table 1: Kriptopara Getirilerine İlişkin Tanımsal İstatistikler

\begin{tabular}{|l|l|l|l|l|l|l|l|l|l|l|}
\hline & btc & eth & usdt & xrp & bch & link & bnb & ltc & usdc & ada \\
\hline Minimum & -0.45559 & -0.5470 & -0.03922 & -0.39314 & -0.56125 & -0.6175 & -0.55178 & -0.44655 & -0.02956 & -0.5033 \\
\hline Maksimum & 0.16585 & 0.17388 & 0.04024 & 0.22875 & 0.34377 & 0.48416 & 0.19346 & 0.22821 & 0.03178 & 0.18354 \\
\hline Medyan & 0.00160 & 0.00104 & 0,00000 & -0.00043 & -0.00032 & 0.00172 & 0.00116 & -0.00077 & 0,00000 & 0,00239 \\
\hline Ortalama & $\mathbf{0 . 0 0 2 0 6}$ & $\mathbf{0 . 0 0 1 6 8}$ & $\mathbf{- 0 . 0 0 0 0 1}$ & $-\mathbf{0 . 0 0 0 4 5}$ & $\mathbf{0 . 0 0 1 1 2}$ & $\mathbf{0 . 0 0 5 3 4}$ & $\mathbf{0 . 0 0 1 6 6}$ & $\mathbf{0 . 0 0 0 2 5}$ & $-\mathbf{0 . 0 0 0 0 2}$ & $\mathbf{0 . 0 0 1 2 6}$ \\
\hline Standart Sapma & 0.03878 & 0.04741 & 0.00592 & 0.03946 & 0.05473 & 0.06759 & 0.04819 & 0.04778 & 0.00541 & 0.05267 \\
\hline VaR & $\mathbf{0 . 1 0 3 5 1}$ & $\mathbf{0 . 1 4 2 5 9}$ & $\mathbf{0 . 0 1 3 0 9}$ & $\mathbf{0 . 1 1 5 2 7}$ & $\mathbf{0 . 1 5 8 2 8}$ & $\mathbf{0 . 1 6 3 3 9}$ & $\mathbf{0 . 1 2 8 4 2}$ & $\mathbf{0 . 1 3 6 8 9}$ & $\mathbf{0 . 0 1 2 5 8}$ & $\mathbf{0 . 1 2 9 2 3}$ \\
\hline CVaR & 0.17353 & 0.21722 & 0.02113 & 0.16643 & 0.25167 & 0.25055 & 0.21689 & 0.20488 & 0.01929 & 0.20692 \\
\hline
\end{tabular}

Stokastik baskınlık bir rastlantı değişkeninin dağılımından bağımsız olma özelliği taşıyan ve aslında dağılımı oluşturan değerlerin tamamını dikkate alan bir ölçüttür (Hanoch ve Levy, 1969). İstatistik olarak Stokastik Baskınlık, tercih edilen bir beklentinin birikimli dağılım değerinin hiçbir zaman ikinci tercih olanın birikimli dağılımını aşmaması durumudur ve bu tanım kısaca FSD tanımı olarak verilmektedir (Hadar ve Russell, 1969). Bir x raslantı değişkeninin tüm gerçel değerleri $(x \in R)$ için $f(x)$ olasılık fonksiyonunu ve

$$
F(x)=\int_{-\infty}^{x} f(t) d t
$$

olarak verilen kümülatif dağılımı dikkate alalım. $\mathrm{f}$ ve $\mathrm{g}$ gibi herhangi iki olasılık dağılımları tüm $\mathrm{x} \in \mathrm{R}$ değerleri için $G(x) \geq F(x)$ koşulunu sağlıyorlarsa "f g'ye birini derece stokastik baskındır" denir ve $f \geqslant_{1} g$ ile gösterilir. Bu tanıma göre, f'in beklenen faydası g'nin beklenen faydasından küçük değilse $f g^{\prime} y e$ birinci derece stokastik baskındır. Eğer tüm $x \in R$ değerleri için

$$
\int_{-\infty}^{x} G(t) d t \geq \int_{-\infty}^{x} F(t) d t
$$

koşulu sağlanıyorsa "f g'ye ikinci derece stokastik baskındır" denir ve $\boldsymbol{f} \geqslant_{\mathbf{2}} \boldsymbol{g}$ ile gösterilir. Bir raslantı değişkeni olan x'in bir eşik değer olarak $\eta$ hedefi için ikinci dereceden stokastik baskınlık ilişkisi tüm $\eta \in R$ değerleri için $E\left([\eta-f]_{+}\right) \leq E\left([\eta-g]_{+}\right)$olarak tanımlanır. Bu tanıma göre, f dağılımı g dağılımına göre daha tahmin edilebilir veya daha az risk içerir şeklinde yorumlanır.

\section{BULGULAR}

İkinci dereceden stokastik baskınlık karşılaştırmaları bir önceki bölümde tanımda verilen formülle elde edilmiş ve Tablo 2'de sunulmuştur.

\begin{tabular}{|c|c|c|c|c|c|c|c|c|c|c|c|}
\hline rank & & btc & eth & usdt & xrp & bch & link & bnb & Itc & usdc & ada \\
\hline 4 & btc & - & Etkin & & & & Etkin & Etkin & & & Etkin \\
\hline 2 & eth & & - & & & & Etkin & & & & \\
\hline 9 & usdt & Etkin & Etkin & - & Etkin & Etkin & Etkin & Etkin & Etkin & Etkin & Etkin \\
\hline 7 & xrp & Etkin & Etkin & & - & Etkin & Etkin & Etkin & Etkin & & Etkin \\
\hline 6 & bch & Etkin & Etkin & & & - & Etkin & Etkin & Etkin & & Etkin \\
\hline 1 & link & & & & & & - & & & & \\
\hline 3 & bnb & & Etkin & & & & Etkin & - & & & Etkin \\
\hline 5 & Itc & Etkin & Etkin & & & & Etkin & Etkin & - & & Etkin \\
\hline 8 & usdc & Etkin & Etkin & & Etkin & Etkin & Etkin & Etkin & Etkin & - & Etkin \\
\hline \multirow[t]{2}{*}{2} & ada & & Etkin & & & & Etkin & & & & Etkin \\
\hline & Toplam & 5 & 8 & 0 & 2 & 3 & 9 & 6 & 4 & 1 & 8 \\
\hline
\end{tabular}

Table 2: İkili Karşılaştırmalarla Etkinlik Sonuçları

Tablo 2'den, sütunlarda ismi yazan bir kripto paranın satırlarda yer alan kripto paraya göre etkin olup olmadığı bilgisi verilmektedir. Örneğin, 10 kripto para içerisinden biri olarak link diğer 9 para birimine etkindir, diğer bir ifade ile ikinci dereceden stokastik baskındır. Bir kripto para getiri serisinin kendisine baskın olduğu ya da olamadığı gibi bir durum söz konusu olamayacağından bu hücreler ('-' işareti ile) boş bırakılmıştır. Usdt kripto para biriminin ise hiç etkinlik alamayan bir kripto para olduğu görülmektedir. Hücrelerdeki etkinlik daha açık bir ifade ile şu şekilde yorumlanabilir; örneğin eth ve btc kripto parabirimlerinin getirileri düşükten yükseğe doğru olacak şekilde kayıptan kazanca 
doğru sıralanmış olsun. Herhangi bir eşik getiri düzeyine göre; bu eşik düzeyinden daha düşük tüm mümkün getirilerin ortalaması eth kripto para birimi için daha düşüktür. Bu nedenle eth kripto para birimi btc kripto para birimine göre ikinci dereceden stokastik baskınlık kriteri açısından etkindir. Dolayısıyla Tablo 2'de elde edilen sonuçlara bir bütün olarak bakıldığında da varılacak sonuçlar aşağıdaki alt başlıkta verilmektedir.

\section{SONUÇ}

Yüksek risk ölçümleri potansiyel kayıpların karşılanması için yüksek risk sermayesi gerektirmektedir ve fiyatları ilgi çekecek düzeyde artış gösteren kriptopara birimleri için yasal düzenlemeler eksiktir. Yatırımlarının genellikle riskli olduğu ve finansal olarak güvenli olmadığı ilgili çalışmalarda da değinilen kriptopara birimleri arasında tercih yaparken yatırımcılar dikkatli olmalıdırlar. Bu nedenle çalışmada elde edilen nicel sonuçlar yüksek finansal riske sahip olan ancak herhangi bir kontrole tabi olmayan pozisyonlardan korumak için oldukça önemlidir.

Çalışmada kullanılan 10 kripto para getirilerinin ikinci dereceden stokastik baskınlık kriteri ile birbirlerine göre etkinlik karşılaştırmalarından aşağıdaki sonuçlar elde edilebilmektedir:

$\checkmark \quad$ link diğer tüm para birimlerine göre etkin bir para birimidir.

$\checkmark \quad$ link'ten sonra en etkin para birimleri ada ve eth'dir.

$\checkmark \quad$ Diğer para birimlerinin hiç birine karşı etkinliği olmayan usdt para birimidir.

$\checkmark \quad$ Kripto para birimleri yatırım aracı olarak portföye dahil etmek düşünüldüğünde, tabloda elde edilen etkinlik sırasına göre etkin parabirimlerine öncelik verilebilir.

\section{KAYNAKÇA}

Anyfantaki, S., \& Topaloglou, N. (2018). Diversification, integration and cryptocurrency market. Integration and Cryptocurrency Market (March 29, 2018).

Akkuş, H. T., \& Çelik, I. (2020). Modeling, Forecasting the Cryptocurrency Market Volatility and Value at Risk Dynamıcs of Bitcoin. Muhasebe Bilim Dünyası Dergisi, 22(2), 296-312.

Atıcı, G. (2020). Dijital Ekonomi, Blokzinciri ve Finansal Sistem, Nobel Akademik Yayıncılık, 1. Basım.

Azimov, J., \& Alkan, U. (2019). Bitcoin Fiyatları ile Çin Ve Rusya'nın Seçilmiş Finansal Göstergeleri Arasındaki İlişkinin Ekonometrik Açıdan Incelenmesi. Avrasya Sosyal ve Ekonomi Araştırmaları Dergisi, 6(10), 165-187.

Bartos, J. (2015). Does Bitcoin follow the hypothesis of efficient market?. International Journal of Economic Sciences, 4(2), 10-23.

Belhadj, H., \& Ben Hamad, S. (2019). Is Bitcoin Good for Portfolio Diversification: Genetic Algorithm and Stochastic Dominance Approach. Is Bitcoin Good for Portfolio Diversification: Genetic Algorithm and Stochastic Dominance Approach (November 30, 2019).

Bouri, E., Lucey, B., \& Roubaud, D. (2020). Cryptocurrencies and the downside risk in equity investments. Finance Research Letters, 33, 101211.

Chakravarty, S., \& Sarkar, P. (2020). An Introduction to Algorithmic Finance, Algorithmic Trading and Blockchain. Emerald Group Publishing.

CoinMarketCap, [Çevrimiçi kaynak]. https://coinmarketcap.com/ [Erişim tarihi: 26 Eylül 2020].

Dyhrberg, A.H. (2016). Bitcoin, gold and the dollar-A GARCH volatility analysis. Finance Research Letters, 16, 85-92.

Ertuğrul, M. (2019). Kripto Paraların Volatilite Dinamiklerinin İncelenmesi: Garch Modelleri Üzerine Bir Uygulama. Yönetim ve Ekonomi Araştırmaları Dergisi, 17(4), 59-71.

Gkillas, K., \& Katsiampa, P. (2018). An application of extreme value theory to cryptocurrencies. Economics Letters, 164, $109-111$.

Glaser, F., Haferhorn, M., Weber, M.C., Zimmarmann, K., Siering, M.b (2014). “Bitcoin - Asset or currency? Revealing users' hidden intentions." ECIS 2014 Tel Aviv.

Gül, Y. (2020). Kripto Paralar ve Portföy Çeşitlendirmesi. Sosyal Bilimler Dergisi/Journal of Social Sciences, (65).

Güleç, Ö. F., Çevik, E. \& Bahadır, N. (2018). Bitcoin ile Finansal Göstergeler Arasındaki İlişkinin İncelenmesi. Kırklareli Üniversitesi Iktisadi ve Idari Bilimler Fakültesi Dergisi, 7(2), 18-37.

Güleç, T. C., \& Aktaş, H. (2019). Kripto Para Birimi Piyasalarında Etkinliğin Uzun Hafıza Ve Değişen Varyans Özelliklerinin Testi Yoluyla Analizi. Eskişehir Osmangazi Üniversitesi Iktisadi ve Idari Bilimler Dergisi, 14(2), 491-510.

Jiménez, I., Mora-Valencia, A., \& Perote, J. (2020). Risk quantification and validation for Bitcoin. Operations Research Letters, 48(4), $534-541$. Jorion, P. (2000). Value At Risk, The New Benchmark for Managing Financial Risk, New York, Second Edition, McGraw-Hill. 
Kanat, E. \& Öget, E. (2018). Bitcoin ile Türkiye ve G7 Ülke Borsaları Arasındaki Uzun ve Kısa Dönemli İlişkilerin İncelenmesi. Finans Ekonomi ve Sosyal Araştırmalar Dergisi (FESA), 3(3), 601-614.

Karaağaç, G. A., \& Altınırmak, S. (2018). En yüksek piyasa değerine sahip on kripto paranın birbirleriyle etkileşimi. Muhasebe ve Finansman Dergisi, (79), 123-138.

Katsiampa, P. (2017). Volatility estimation for Bitcoin: A comparison of GARCH models. Economics Letters, 158 , 3-6.

Katsiampa, P., Corbet, S., \& Lucey, B. (2019). Volatility spillover effects in leading cryptocurrencies: A BEKK-MGARCH analysis. Finance Research Letters, 29, 68-74.

Kayral, i. E. (2020). En Yüksek Piyasa Değerine Sahip Üç Kripto Paranın Volatilitelerinin Tahmin Edilmesi. Journal of Financial Researches \& Studies/Finansal Arastirmalar ve Calismalar Dergisi, 11(22)

Kılıç, Y., \& Çütcü, İ. (2018). Bitcoin fiyatları ile borsa istanbul endeksi arasındaki eşbütünleşme ve nedensellik ilişkisi. Eskişehir Osmangazi Üniversitesi Iktisadi ve Idari Bilimler Dergisi, 13(3), 235-250.

Konuşkan, A., Teker, T., Ömürbek, V., \& Bekci, İ. (2019). Kripto Paraların Fiyatları Arasındaki Ilişkinin Tespitine Yönelik Bir Araştırma. Suleyman Demirel University Journal of Faculty of Economics \& Administrative Sciences, 24(2).

Koutmos, D. (2019). Market risk and Bitcoin returns. Annals of Operations Research, 1-25. https://doi.org/10.1007/s10479-019-03255-6.

Kuzu, S., \& Çelik, İ. E. (2020). Bitcoin Alternatif Yatırım Aracı ya da Hedge Enstrümanı Olarak Düşünülebilir mi?. Anemon Muş Alparslan Üniversitesi Sosyal Bilimler Dergisi, 8(2), 603-613.

Levy, H. (1992). Stochastic dominance and expected utility: survey and analysis. Management science, 38(4), 555-593.

Likitratcharoen, D., Ranong, T. N., Chuengsuksomboon, R., Sritanee, N., \& Pansriwong, A. (2018). Value at risk performance in cryptocurrencies. The Journal of Risk Management and Insurance, 22(1), 11-28.

Osterrieder, J. \& Lorenz, J. (2017). A statistical risk assessment of Bitcoin and its extreme tail behavior. Annals of Financial Economics, 12 (01), 1750003.

Phillip, A., Chan, J. \& Peiris, S. (2018). A new look at cryptocurrencies. Economic Letters. 163, 6-9.

Platanakis, E., \& Urquhart, A. (2020). Should investors include bitcoin in their portfolios? A portfolio theory approach. The British Accounting Review, 52(4), 100837.

Rockafellar, R. T., \& Uryasev, S. (2002). Conditional value-at-risk for general loss distributions. Journal of banking \& finance, $26(7), 1443-1471$.

Silahli, B., Dingec, K. D., Cifter, A., \& Aydin, N. (2019). Portfolio value-at-risk with two-sided Weibull distribution: Evidence from cryptocurrency markets. Finance Research Letters, 101425.

Songur, M. (2019). Bitcoin Piyasasında Balonlar: Genelleştirilmiş Eküs ADF Testi. Anemon Muş Alparslan Üniversitesi Sosyal Bilimler Dergisi, 7(6), 187-192.

Stavroyiannis, S. (2018). Value-at-risk and related measures for the Bitcoin. The Journal of Risk Finance, 19(2), 127-136.

Şahin, E. E., \& Özkan, O. (2018). Asimetrik Volatilitenin Tahmini: Kripto Para Bitcoin Uygulaması. Bilecik Şeyh Edebali Üniversitesi Sosyal Bilimler Enstitüsü Dergisi, 3(2), 240-247.

Topaloglou, N., \& Tsomidis, G. (2018). Investors' Behavior in Cryptocurrency Market. Working Paper.

Uryasev, S. (2000). Conditional Value-at-Risk: Optimization Algorithms and Applications. Financial Engineering News, 14, February 2000.

Uyar, U., Kelten, G. S., \& Moralı, T. (2020). Yatırımcılar için Teknik Analiz: Bitcoin ve Ethereum Uygulamaları. Finansal Araştırmalar ve Çalışmalar Dergisi, 12(23), 669-687.

Yağmur, A., \& Mangır, F. (2020). Bitcoin Piyasasında Rassal Yürüyüş Hipotezi. Yönetim ve Ekonomi Araştırmaları Dergisi, 18(2), 161-175. 